\title{
ASTHMA
}

\section{Self-management of asthma in general practice, asthma control and quality of life: a randomised controlled trial}

\author{
B P A Thoonen, T R J Schermer, G van den Boom, J Molema, H Folgering, \\ R P Akkermans, R Grol, C van Weel, C P van Schayck
}

Thorax 2003;58:30-36

See end of article for authors' affiliations

Correspondence to:

Dr B P A Thoonen,

Department of General

Practice/Family Medicine,

University of Nijmegen,

PO Box 9101, $6500 \mathrm{HB}$

Nijmegen, The

Netherlands;

b.thoonen@hag.umen.nl

Revised version received 17 August 2002

Accepted for publication

14 September 2002

\begin{abstract}
Background: A study was undertaken to determine the effectiveness of asthma self-management in general practice.

Methods: Nineteen general practices were randomly allocated to usual care (UC) or self-management (SM). Asthma patients were included after confirmation of the GP diagnosis. Follow up was 2 years. Patients kept diary cards and visited the lung function laboratory every 6 months. Outcomes were number of successfully treated weeks, limited activity days, asthma specific quality of life, forced expiratory volume in 1 second $\left(\mathrm{FEV}_{1}\right), \mathrm{FEV}_{1}$ reversibility, concentration of histamine provoking a fall in $\mathrm{FEV}$, of $20 \%$ or more ( $\mathrm{PC}_{20}$ histamine), and amount of inhaled steroids.

Results: A total of 214 patients were included in the study (104 UC/110 SM; one third of the total asthma population in general practice); $62 \%$ were female. The mean percentage of successfully treated weeks per patient in the UC group was $72 \%$ (74/103 weeks) compared with $78 \%(81 / 105$ weeks) in the SM group ( $p=0.003)$. The mean number of limited activity days was $1.2(95 \% \mathrm{Cl} 0.5$ to 1.9 ) in the SM group and $3.9(95 \% \mathrm{Cl} 2.5$ to 5.4$)$ in the UC group. The estimated increase in asthma quality of life score was 0.10 points per visit in the UC group and 0.21 points per visit in the SM group $(p=0.055) . F E V_{1}, F E V$, reversibility, and $P_{2}$ histamine did not change. There was a saving of 217 puffs of inhaled steroid per patient in favour of the SM group $(p<0.05)$.

Conclusion: Self-management lowers the burden of illness as perceived by patients with asthma and is at least as effective as the treatment usually provided in Dutch primary care. Self-management is a safe basis for intermittent treatment with inhaled corticosteroids.
\end{abstract}

A sthma is a chronic inflammatory pulmonary disease which has a significant socioeconomic impact on patients and their families. ${ }^{1}$ The finding that airway inflammation is the key underlying process in asthma has led to recommendations that inhaled corticosteroids should be introduced early in the management of the disease..$^{2-5}$ Despite these guidelines and increasing knowledge, asthma morbidity is still considerable. Poor compliance with prescribed inhaled treatment is an important cause of uncontrolled disease..$^{6-10}$ Poor control of asthma is associated with an impaired quality of life $\mathrm{f}^{11}{ }^{12}$ and is calculated to be responsible for three quarters of the total costs of asthma. ${ }^{1}$ It is therefore likely that improving compliance with treatment will lead to improvements in asthma control and quality of life. Low compliance results in underuse of medication, but asthma is also characterised by overuse, particularly of inhaled medication. Overuse of inhaled steroids may increase the number of unwanted side effects without additional benefits. There are indications that inhaled steroids can be tapered off or stopped during certain periods, ${ }^{13}$ or at least reduced to the minimal effective daily dose that provides adequate control of the disease.$^{14}$ Optimising treatment for the individual patient may balance benefits and risks and lead to a more efficient and cost effective treatment.

Patients with mild asthma treated by their general practitioner (GP) may be suitable for intermittent treatment, ${ }^{15}$ providing adequate control of their asthma is maintained. Implementing guided self-management takes a considerable effort ${ }^{16}$ and studies on effectiveness and use in general practice are needed. Most published studies have shown self-management to be effective in patients with more severe asthma or those with frequent exacerbations, ${ }^{17}$ and it is unknown whether guided self-management may also be effective in patients with milder asthma. Loss of asthma con- trol occurs less frequently and there is lower impact on quality of life, ${ }^{18}$ leaving limited room for improvement. The aim of this study was to determine if guided self-management can provide a safe treatment strategy for asthmatic patients in general practice.

\section{METHODS}

\section{Practices}

General practices were recruited from two pools; the first were in and around the city of Eindhoven and the second were practices from our department's academic research network. Recruitment was stopped when a sufficient number of participating practices was reached. Practices rather than individual patients were randomised to prevent contamination. To prevent management bias, stratified cluster randomisation was performed based on the type of practice (one GP, two GPs, group practice), the number of identified asthmatics (above or below the median number (14) of identified patients), and use of computerised prescriptions (yes, no).

\section{Selection of patients}

GPs identified all asthma patients aged between 16 and 60 years using problem list coding (ICPC), prescription data from practice records, the annual influenza vaccination campaign list, and prescription data provided by the local pharmacist. Identified patients received an invitation letter from their GP to participate in the study. Patients willing to participate were invited for assessment in a lung function laboratory. Inclusion and exclusion criteria are summarised in box 1 . Inclusion criteria were measured for all patients without exclusion criteria. Patients with a pre-bronchodilator forced expiratory volume in 1 second $\left(\mathrm{FEV}_{1}\right)$ of $<80 \%$ predicted were treated with $800 \mu \mathrm{g}$ budesonide twice daily during a 6 week run in period 


\section{Box 1 Inclusion and exclusion criteria}

\section{Exclusion criteria}

- Smoking history of 15 or more pack years

- Serious diseases other than asthma with a low survival rate

- Exacerbations during the month before the start of the study

- Other diseases which influence bronchial symptoms and/or lung function such as heart failure, sarcoidosis

- Inability to inhale medication correctly or to measure and record peak flow adequately and unlikely that this can be taught

Inclusion criteria

- Treated for asthma by the GP and

- Age 16-60 years and

- $\mathrm{FEV}_{1}>40 \%$ of predicted value and $>55 \%$ of predicted value 15 minutes after inhalation of $800 \mu \mathrm{g}$ salbutamol or 6 weeks after inhalation of $800 \mu g$ budesonide twice daily and

- $\mathrm{FEV}_{1}$ reversibility (after bronchodilation with $800 \mu \mathrm{g}$ salbutamol metered dose inhaler or 8 weeks treatment with $800 \mu \mathrm{g}$ budesonide twice daily) of at least $10 \%$ of the predicted value or $\mathrm{PC}_{20}$ histamine of $8 \mathrm{mg} / \mathrm{ml}$.

to obtain optimal asthma control at baseline and to enable proper assessment of the personal best peak flow of patients in the self-management group.

\section{Self-management programme}

The self-management (SM) programme started with four individual training visits of 30,20 , and $2 \times 10$ minutes, respectively, at the GP's surgery during a period of 3 months. These visits consisted of tailored education ${ }^{19}$ and instructions on how to use a personalised written self-treatment plan. Patients weekly recorded morning and evening peak flow values and the presence of asthma symptoms. Three alarm symptoms were defined: waking at night because of asthma (yellow zone), use of bronchodilator $>4$ times a day (red zone), and increased dyspnoea without exertion (purple zone). In the presence of alarm symptoms or a fall in peak flow values below $80 \%, 60 \%$, or $40 \%$ of the personal best value, patients were instructed to start daily measurements of peak flow and symptoms. Self-treatment instructions for budesonide and oral steroids (30 mg prednisolone per day for 1 week) are summarised in box 2 . After the training visits biannual control visits were recommended over a follow up period of 21 months. At each control visit (10 minutes) GPs checked the patients' performance of the self-treatment instructions. It was left to the initiative of the GP and patient if and when these control visits took place. Training in the inhalation technique and peak flow measurement was repeated at each visit.

\section{Usual care}

In the usual care (UC) group GPs were instructed to treat all asthma patients as usual; for most GPs this is according to the guidelines of the Dutch College of Family physicians ${ }^{20}{ }^{21}$ which recommend follow up visits ( 10 minutes) every 3-6 months. These national guidelines are largely comparable to most international guidelines but do not include self-management so far. At the start of the programme, one visit to the GP's surgery was scheduled to instruct patients on the use and dosage of their inhaled steroids (budesonide $200 \mu \mathrm{g}$ Turbuhaler).

\section{Study medication}

The aim of the self-treatment plan was individual optimisation of treatment with inhaled corticosteroids. To study the effects on the amount of inhaled steroids used, all study patients were treated with budesonide $200 \mu \mathrm{g} /$ dose dry powder inhaler (Turbuhaler). In the UC group the daily dosage was determined by the patients' GPs according to the national

\section{Box 2 Summary of self-treatment plan}

\section{Step-up instructions}

- Peak flow deteriorates $<80 \%$, peak expiratory flow rate (PEFR) $\geqslant 60 \%$ of personal best value (PBV) for 2 out of 3 consecutive days:

- double budesonide dosage;

- in case of insufficient response within 3 weeks. again double budesonide dosage.

- Peak flow deteriorates $<60 \%$, PEFR $\geqslant 40 \%$ of PBV for 2 out of 3 consecutive days:

- increase budesonide dosage to $800 \mu g$ twice daily;

- in case of insufficient response within 2 days, start course of oral prednisolone

- and contact your GP.

- Peak flow deteriorates $<40 \%$ of PBV:

- if sufficient response to bronchodilator, start course of oral prednisolone;

- Otherwise, immediately contact your GP

Step-down instructions

- Peak flow improves to $\geqslant 40 \%$, PEFR $<60 \%$ of PBV:

- continue the current budesonide dosage until PEFR is $>80 \%$ of PBV.

- Peak flow improves to $\geqslant 60 \%$, PEFR $<80 \%$ PBV:

- continue the current budesonide dosage until PEFR is $>80 \%$ of PBV.

- Peak flow improves to $\geqslant 80 \%$ of PBV:

- halve budesonide dosage when PEFR $\geqslant 80 \%$ for a period of 6 weeks.

guidelines for treatment of asthma. ${ }^{20}{ }^{21}$ Both groups received regular inhalation instructions.

\section{Outcome measures}

The main outcome measures of the study were asthma control, asthma specific quality of life, and lost activity days. Asthma control was defined using the following parameters:

- percentage of successfully treated weeks;

- changes in post-bronchodilator $\mathrm{FEV}_{1}(800 \mu \mathrm{g}$ salbutamol once daily through spacer);

- changes in reversibility of $\mathrm{FEV}_{1}$ as percentage of the predicted value; and

- changes in concentration of histamine provoking a fall in $\mathrm{FEV}_{1}$ of $20 \%$ or more ( $\mathrm{PC}_{20}$ histamine).

Patients visited the lung function laboratory every 6 months over a period of 2 years. Diary cards were collected and checked for errors. At each visit post-bronchodilator $\mathrm{FEV}_{1}$, reversibility, and asthma specific quality of life were measured. $\mathrm{PC}_{20}$ histamine ${ }^{22}$ was measured at baseline and after 2 years. Assessors were not blinded to study group allocation.

A successfully treated week was defined as a week in which acceptable asthma control in terms of perceived dyspnoea was maintained. Patients in both groups weekly recorded dyspnoea on a modified Borg scale ranging from 0 (no dyspnoea) to 10 (maximally severe dyspnoea). ${ }^{23}$ The median dyspnoea score of all individual recordings was considered as the cut off point between successfully and unsuccessfully treated weeks. Weeks with a dyspnoea score equal to or below this cut off point were counted as successful. Successfully treated weeks were calculated if patients had recorded at least 52 weeks. To correct for differences in the number of recorded weeks, successfully treated weeks were standardised to the percentage of recorded weeks. An example of this procedure is summarised graphically for one patient in fig 1 . In addition to the dyspnoea scores, patients weekly recorded the number of days during the previous week with limited activities due to asthma.

Asthma specific quality of life was measured using the Asthma Quality of Life Questionnaire (AQLQ) developed by Juniper et al. ${ }^{11}{ }^{12}$ An individual increase of 0.5 points on the 
Table 1 Characteristics of participating practices

\begin{tabular}{lll}
\hline & Self-management & Usual care \\
\hline Type of practices & & \\
1 GP & $2(25 \%)$ & $1(9 \%)$ \\
2 GPs & $3(37 \%)$ & $5(46 \%)$ \\
$>2$ GPs & $3(38 \%)$ & $5(45 \%)$ \\
$\quad$ Total & 8 & 11 \\
No $(95 \%$ Cl) of asthmatics per 1000 patients & $7.6(5.6$ to 9.6$)$ & $9.0(4.9$ to 13.2) \\
Computerised prescription & $7 / 1$ & $8 / 3$ \\
Yes/no & & \\
\hline
\end{tabular}

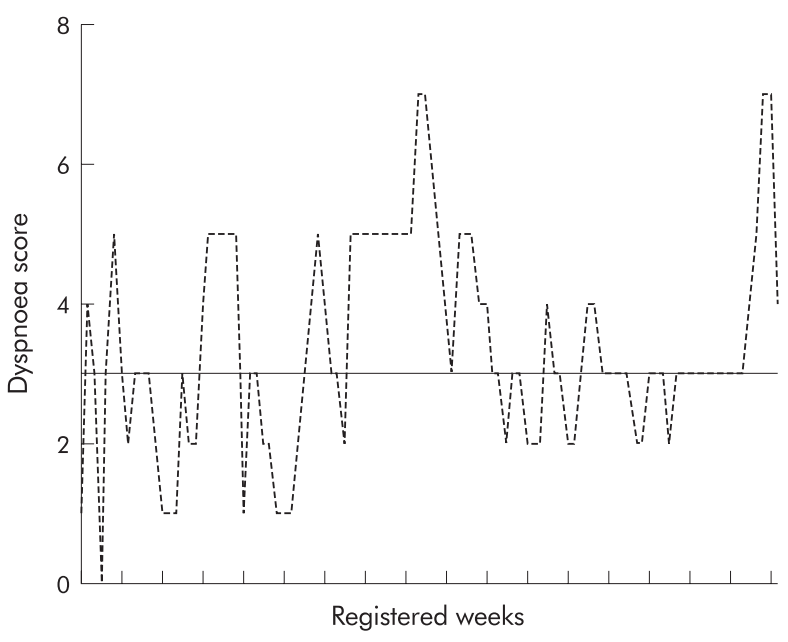

Figure 1 Calculation of successfully treated weeks for one patient in the usual care group. Number of registered weeks $=104$; median dyspnoea score $=3$; number of weeks with dyspnoea $\leqslant$ median dyspnoea score $=64$; percentage of successfully treated weeks $=$ $(64 / 104) \times 100=61.5 \%$.

overall score or one of the domain scores was considered a minimal clinically relevant improvement (MCRI).

Secondary outcome measures were the number of puffs of budesonide, number of dose equivalents of short acting bronchodilators, number of short courses of oral prednisolone and antibiotics, and number of GP diagnosed exacerbations. The number of puffs of budesonide used was counted at each laboratory visit by subtracting the number of remaining dosages in each Turbuhaler inhaler issued from the total number of dosages prescribed over the previous period. The amount of short acting bronchodilators was based on the weekly recordings of patients. Based on presumed differences in deposition between metered dose inhalers and dry powder inhalers, dry powder inhaler dosages were halved to obtain dose equivalents. ${ }^{24} 25$ Short acting bronchodilators were thus converted to equipotent doses of either salbutamol or ipratropium metered dose inhalers in $\mu \mathrm{g} /$ day. Exacerbations were recorded by GPs at each scheduled and unscheduled visit. GPs recorded an exacerbation if two of the following three criteria were present: increased asthma symptoms, fall in peak flow below $80 \%$ of predicted value, and increased use of bronchodilators. Short courses of prednisolone and antibiotics prescribed were recorded as other indicators of exacerbations.

\section{Power calculation}

The power calculation for determining the trial size was based on the AQLQ, with a change of 0.5 points between groups being considered clinically relevant. Based on multilevel analysis, we assumed an average inclusion of 10 patients per practice and an interclass correlation of 0.02 . With an observed standard deviation of 0.9 , a power of $90 \%$ and an $\alpha$ of
0.05 (two sided), 17 practices with a total number of 170 patients were needed. After taking into account a drop out rate of $20 \%$, it was calculated that 213 patients were needed.

\section{Analysis of data}

Outcome parameters were evaluated on an intention to treat basis and by repeated measurement techniques. ${ }^{26} \mathrm{~A}$ random coefficient linear model (multilevel) with an autoregressive error structure was performed on post-bronchodilator FEV and AQLQ scores. Reversibility of $\mathrm{FEV}_{1}$ (\% predicted value) was analysed in a similar non-linear model. Baseline values, age, sex, and smoking were entered as possible confounders. All analyses were performed using the PROC MIXED procedures by SAS. ${ }^{27}$ Transformed $\mathrm{PC}_{20}$ values $\left({ }^{2} \log \mathrm{PC}_{20}\right.$ ) were compared with a Student's $t$ test. If there was a significant difference over time in any quality of life domain, the proportions of subjects with a relevant change over 2 years (MCID) were compared using $\chi^{2}$ tests. The amounts of medication used in both groups and the percentages of successfully treated weeks were compared using a $t$ test when normally distributed and a Mann-Whitney U test when not normally distributed.

\section{RESULTS}

Of 38 practices invited to participate in the study, 19 agreed to do so. Table 1 shows the characteristics of the participating practices in both treatment groups. The flow chart in fig 2 summarises the number of patients. During the pretreatment phase 15 patients dropped out of the programme and a further five dropped out before the first follow up assessment. A total of 193 patients (98 SM) were therefore included in the intention to treat analysis. The baseline characteristics of the patients included in the intention to treat analysis are shown in table 2. The treatment groups did not differ in general or clinical characteristics at baseline apart from a higher proportion of patients reporting a recent episode of aggravated asthma symptoms and lower AQLQ scores in the SM group. Fourteen patients in the SM group and 16 in the UC group did not use bronchodilator medication during the study. At baseline, long acting $\beta_{2}$ agonists were used by six patients in the SM group and by four in the UC group. During the study 12 SM and five UC patients used a long acting $\beta_{2}$ agonist; theophyllines were used by three patients in the SM group.

Successfully treated weeks could be calculated for 83 (85\%) and $87(92 \%)$ subjects in the SM and UC groups, respectively. The mean percentage of successfully treated weeks per patient in the SM group was $78 \%$ (95\% CI 75.1 to 80.6) (81/105) recorded weeks compared with $72 \%$ (95\% CI 68.8 to 74.8 ) (74/ 103) recorded weeks in the UC group.

During follow up $79 \%$ of SM and $62 \%$ of UC patients reported one or more limited activity days. When all patients were included, the mean number of limited activity days was 1.9 (95\% CI 0.7 to 3.2) for the SM group and 6.0 (95\% CI 2.6 to 9.4) for the UC group. Closer examination identified two distinct outliers in the UC group with 142 limited activity days and 69 limited activity days, respectively. One of the outliers 


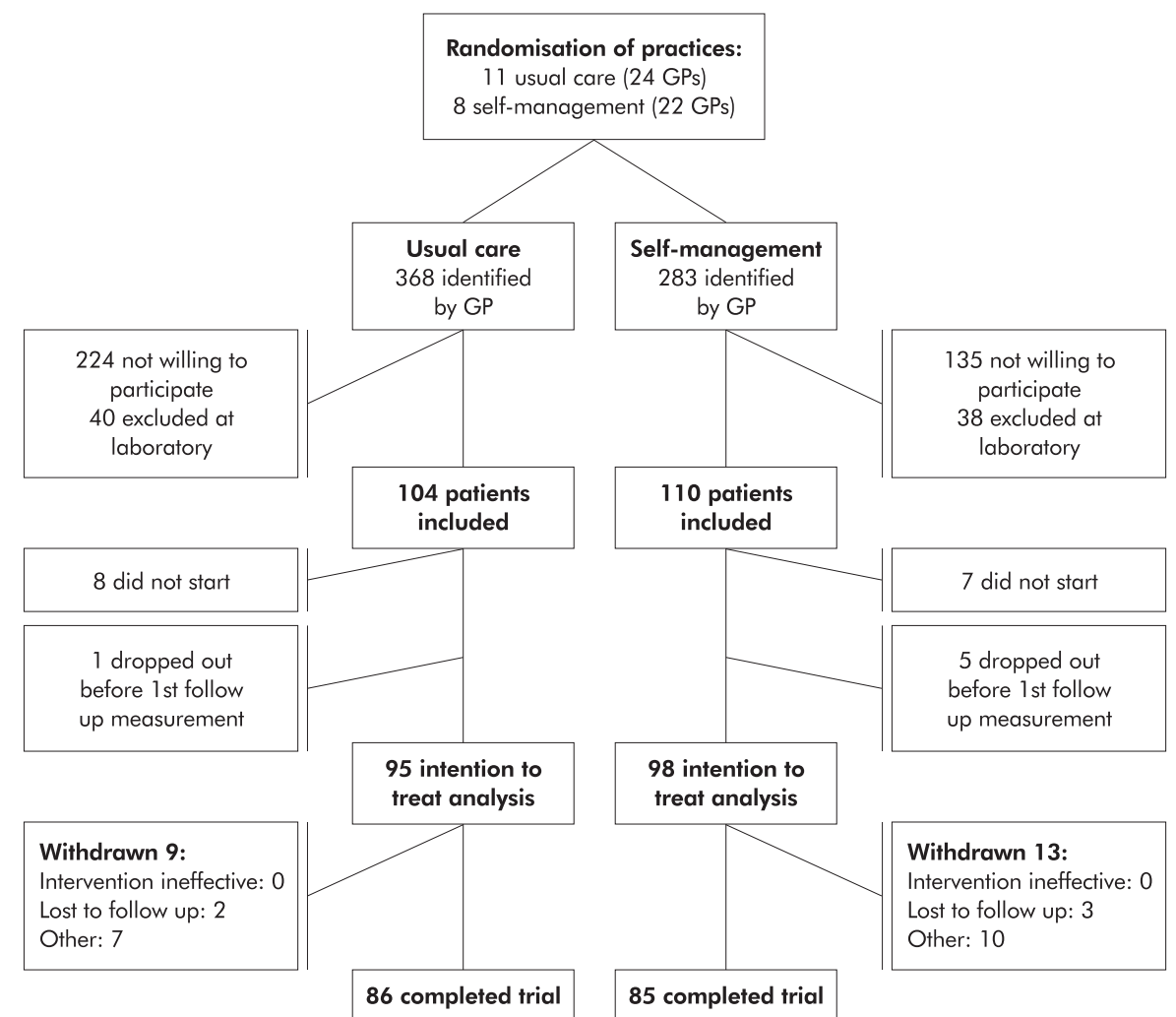

Figure 2 Flow chart showing study participants.

had a period of several months with frequent but short episodes of sick leave due to asthma, the other a 3 month episode of uninterrupted sick leave. In both cases irritant exposure in the workplace explained the high counts. Because of the clear work related cause and the disproportionate impact of these two outliers on the group mean, we decided to exclude subjects above the 98th percentile from the final calculations in both groups. This resulted in a mean number of limited activity days of 1.2 (95\% CI 0.5 to 1.9 ) for the SM group and 3.9 (95\% CI 2.5 to 5.4) for the UC group.

Table 2 Baseline characteristics of study subjects included in the intention to treat analyses

\begin{tabular}{|c|c|c|c|}
\hline & Self-management $(n=98)$ & Usual care $(n=95)$ & $\mathrm{p}$ value \\
\hline Age (years) & $39.6(11.2)$ & $39.3(12.0)$ & 0.859 \\
\hline $\operatorname{Sex}(M / F)$ & $34 / 64$ & $40 / 56$ & 0.394 \\
\hline \multicolumn{4}{|l|}{ Smoking: } \\
\hline Never smokers & $45(46 \%)$ & $54(56 \%)$ & \\
\hline Former smokers & $31(32 \%)$ & $21(22 \%)$ & \\
\hline Current smokers & $22(22 \%)$ & $21(22 \%)$ & 0.254 \\
\hline Pack years* & $5.8(4.5)$ & $5.7(4.5)$ & 0.881 \\
\hline Requiring pretreatment with budesonide $†$ & $34(35 \%)$ & $22(23 \%)$ & 0.077 \\
\hline$\%$ with asthma attack(s) in previous 6 months & $48.5 \%$ & $31.6 \%$ & 0.017 \\
\hline \multicolumn{4}{|l|}{$\mathrm{FEV}_{1}(\%$ predicted value): } \\
\hline Pre-bronchodilator $(\mathrm{BD})$ ** & $84.0(13.1)$ & $86.9(14.2)$ & 0.141 \\
\hline Post-bronchodilator (BD) & $90.0(12.1)$ & $92.6(12.9)$ & 0.135 \\
\hline \multicolumn{4}{|l|}{$\mathrm{FEV}_{1}$ reversibility $(\%)$ (median) $\ddagger$ ** } \\
\hline PostBD - preBD/predicted & $5.0(8.6) \operatorname{IQR}$ & $5.4(6.8) I Q R$ & 0.930 \\
\hline \multicolumn{4}{|l|}{ Bronchial hyperresponsiveness } \\
\hline $\mathrm{PC}_{20}$ geometric mean & 1.20 & 0.97 & 0.442 \\
\hline Initial dose of inhaled steroids & & & 0.622 \\
\hline None & $12(12 \%)$ & $16(17 \%)$ & \\
\hline Low (<400 $\mu g$ daily or equivalent) & $36(37 \%)$ & $30(32 \%)$ & \\
\hline Intermediate ( $\geqslant 400$ and $<800 \mu g$ daily or equivalent) & $34(35 \%)$ & $37(39 \%)$ & \\
\hline High ( $\geqslant 800 \mu g$ daily or equivalent) & $16(16 \%)$ & $12(12 \%)$ & \\
\hline \multicolumn{4}{|l|}{ Quality of life: } \\
\hline Activities domain & $5.3(1.03)$ & $5.6(0.77)$ & 0.015 \\
\hline Emotions domain & $5.8(1.01)$ & $6.2(0.76)$ & 0.002 \\
\hline Symptoms domain & $5.3(1.03)$ & $5.6(0.90)$ & 0.074 \\
\hline Environment domain & $5.3(1.10)$ & $5.5(1.1)$ & 0.165 \\
\hline Overall score & $5.4(0.872)$ & $5.7(0.771)$ & 0.013 \\
\hline \multicolumn{4}{|c|}{ 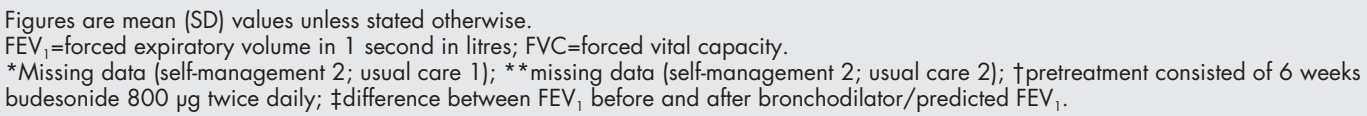 } \\
\hline
\end{tabular}




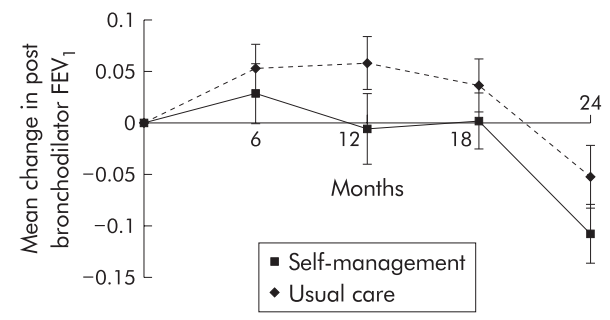

Figure 3 Mean changes from baseline in post-bronchodilator FEV (l) with standard errors.

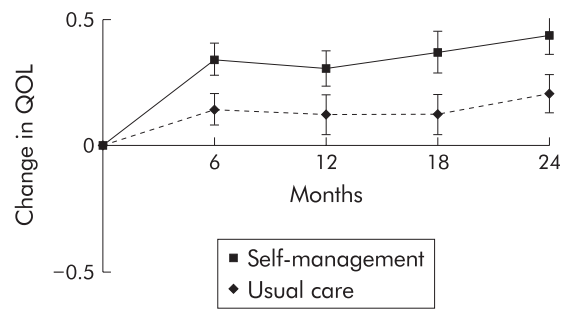

Figure 4 Mean changes from baseline in quality of life (overall score) with standard errors.

As shown in fig 3, the post-bronchodilator $\mathrm{FEV}_{1}$ had an estimated decline rate of $0.048 \mathrm{l} /$ year in the SM group and $0.026 \mathrm{l} /$ year in the UC group $(\mathrm{p}=0.239)$. There were no between group differences in the estimated rate of decline in $\mathrm{FEV}_{1}$ reversibility and $\mathrm{PC}_{20}$ histamine.

Changes from baseline in overall AQLQ score are summarised in fig 4. Based on repeated measurements analysis, the estimated increase in overall asthma quality of life score was 0.10 points per visit in the UC group and 0.21 points per visit in the SM group $(p=0.055)$. Changes in quality of life were also estimated for each of the sub-domains (emotions, activities, symptoms, and environment). There was a significant change between groups only in the emotions domain $(0.02$ points per visit in the UC group; 0.20 points per visit in the SM group; $p=0.006$ ). To determine whether statistically significant changes in quality of life were clinically relevant, we compared proportions of subjects with individual changes of at least 0.5 points. In the emotions domain $41 \%$ of patients from the SM group had an increase of at least 0.5 points compared with $23 \%$ of patients in the UC group $\left(\chi^{2}=8.811\right.$, $\mathrm{p}=0.012$ ).
Mean budesonide usage was 1680 puffs per patient (95\% CI 1538 to 1822) in the SM group and 1897 puffs per patient (95\% CI 1679 to 2115 ) in the UC group, indicating a saving of 217 puffs per patient.

With a median (IQR) dose of 97 (168) $\mu \mathrm{g} /$ day of short acting $\beta_{2}$ bronchodilators in the SM group and 69 (340) $\mu \mathrm{g} /$ day in the UC group, there was no statistically significant difference between the two study groups $(p=0.711$, Mann-Whitney $U$ test). In the SM group a median (IQR) dose of $12(28) \mu \mathrm{g} /$ day of ipratropium was used compared with 35 (114) $\mu \mathrm{g} /$ day in the UC group ( $p=0.607$, Mann-Whitney U test).

Table 3 summarises the indicators of exacerbations. There were no differences in the number of GP diagnosed exacerbations and the number of antibiotics between the two groups, but the SM group had a significantly higher number of courses of oral prednisolone than the UC group $(p=0.015$, Mann-Whitney U test).

\section{DISCUSSION}

Findings from this study indicate that asthma control improved in the SM group in terms of a higher number of successfully treated weeks and fewer limited activity days. There were no major changes in lung function parameters. In the SM group there was a slight improvement in asthma specific quality of life with a clinically relevant improvement in the emotions domain, indicating that patients in this group felt less worried or insecure about the influence of their asthma on daily life. GPs did not diagnose more exacerbations, but the number of oral prednisolone courses was higher in the guided SM group. The study population consisted of approximately one third of all subjects initially identified by GPs. Determinants of willingness to participate and their implications have been discussed extensively elsewhere. ${ }^{15}$ The main implication is that subjects with low or intermediate doses of inhaled corticosteroids at baseline may have been relatively over-represented in this study. Based on initial levels of preand post-bronchodilator $\mathrm{FEV}_{1}$, the observed reversibility and initial dosage of inhaled steroids, included patients appeared to be a representative sample of patients with mild to moderately severe asthma. ${ }^{5182028-30}$

Half of all invited practices participated in this study, which does not differ from previously studied acceptance rates. ${ }^{16}$ Other practice characteristics (table 1) also suggest that participating practices were a representative sample of Dutch general practice, with the restriction that participants have a positive attitude towards self-management.

There have been few randomised controlled trials to date on the effects of guided self-management programmes in family

\begin{tabular}{|c|c|c|}
\hline & Self-management & Usual care \\
\hline \multicolumn{3}{|l|}{ Exacerbations per patient per 2 years $(p=0.678)$} \\
\hline No (\% within group) with 0 exacerbations & $29(36)$ & $33(41)$ \\
\hline No (\% within group) with 1 exacerbations & $28(35)$ & $22(28)$ \\
\hline No (\% within group) with 2 exacerbations & 7 (9) & $12(15)$ \\
\hline No (\% within group) with 3 exacerbations & $7(9)$ & $6(8)$ \\
\hline No (\% within group) with $\geqslant 4$ exacerbations & $9(11)$ & $7(9)$ \\
\hline \multicolumn{3}{|c|}{ Oral prednisolone courses per patient per 2 years $(p=0.015)$} \\
\hline No (\% within group) with 0 courses & $64(70)$ & $80(85)$ \\
\hline No (\% within group) with 1 course & $19(21)$ & $11(12)$ \\
\hline No (\% within group) with 2 courses & $6(7)$ & $1(1)$ \\
\hline No (\% within group) with $\geqslant 3$ courses & $2(2)$ & $2(2)$ \\
\hline \multicolumn{3}{|c|}{ Courses of antibiotics per patient per 2 years $(p=0.643$ ) } \\
\hline No (\% within group) with 0 courses & $71(78)$ & $71(76)$ \\
\hline No (\% within group) with 1 course & 15 (17) & $15(16)$ \\
\hline No (\% within group) with 2 courses & $2(2)$ & $5(5)$ \\
\hline No ( $\%$ within group) with $\geqslant 3$ courses & $3(3)$ & $3(3)$ \\
\hline
\end{tabular}


medicine. As in our study, most have shown limited reductions in symptoms or improvements in lung function and quality of life. Hoskins $e \mathrm{al}^{31}$ showed reductions in morbidity in terms of hospital admission, (emergency) consultations, oral steroid courses, and emergency nebulisations but, because of possible selection bias, superiority of self-management plans could not be proved. Their results suggest that improvements in clinical and morbidity parameters are indeed less likely to occur in patients with mild asthma. This was also concluded by Jones et $a{ }^{32}$ but they may have failed to show results due to the small number of subjects. On the other hand, neither of these studies found that self-management caused unwanted loss of asthma control or increased morbidity. In our study we observed a significantly higher number of patients requiring one or more courses of oral steroids in the SM group. Based on instructions in the self-treatment plan, patients could start an oral course of prednisolone independently, so patients were routinely prescribed one prednisolone course at the third educational session. As there are strong indications that GPs accidentally recorded these prescriptions as true oral prednisolone courses, over-registration may have occurred. Another explanation for the higher number of prednisolone courses may be the larger number of patients with an asthma attack in the previous 6 months and the larger number of patients requiring pretreatment at the start of the study in the SM group. This may indicate that asthma control in the SM group was initially worse than in the UC group. This is also reflected in a lower baseline quality of life.

During the study changes in post-bronchodilator $\mathrm{FEV}_{1}$, $\mathrm{FEV}_{1}$ reversibility, and $\mathrm{PC}_{20}$ did not differ between the groups. In view of these findings, the higher number of oral steroid courses in the SM group can be attributed to a baseline difference between the groups in asthma control. In addition, the use of oral steroids can be biased by instructions in the guided SM programme. Subjects in the SM group were explicitly instructed about when to take oral courses of prednisolone. The increased number of prescriptions may therefore indicate either overtreatment or the self-treatment instructions worked as planned. In instances with more severe loss of asthma control, adequate treatment was initiated without unnecessary delay, which is consistent with the increased number of successfully treated weeks and the lower number of lost activity days.

The number of successfully treated weeks is an indicator of the burden of asthma as perceived by patients. It is based on perceived changes in dyspnoea rather than on perceived levels of dyspnoea. Patients who constantly experience the same high levels of dyspnoea may thus have a relatively higher number of successfully treated weeks. Assuming that the pretreatment phase did result in the highest achievable level of asthma control, constantly high symptom levels are only an indicator of the severity of asthma experienced, not asthma control. Subjects with increased weekly variations in perceived dyspnoea levels will therefore have a lower number of successfully treated weeks. Accordingly, the increased number of successfully treated weeks in the SM group suggests less loss of asthma control in this group. These findings are in accordance with the lower number of limited activity days, but are not strongly reflected in improvements in quality of life. Although it must be kept in mind that symptoms experienced represent a totally different concept from the impact of asthma symptoms on quality of life, it is reasonable to hypothesise that comparable improvements in both outcomes can be observed. There were significant differences in observed changes in quality of life in favour of the SM group. The magnitude of these gains was limited, however. Quality of life was high in both groups at baseline and may have left little room for improvement. The finding that observed baseline differences in quality of life scores completely disappeared after 24 months may indicate that quality of life had been maximised in both groups.
During the study long acting $\beta$ agonists were introduced in updated Dutch guidelines on diagnosis and treatment of asthma. Treatment with long acting $\beta$ agonists was initiated in a relatively higher proportion of patients in the SM group but numbers were too small to allow for reliable statistics. It is therefore unlikely that prescription of long acting $\beta$ agonists substantially contributed to improvements in successfully treated weeks or quality of life in favour of the SM group.

Based on our findings, we conclude that self-management of asthma is at least equally effective as asthma treatment usually provided in Dutch primary care. Asthma selfmanagement provides a safe basis for intermittent treatment with inhaled corticosteroids and lowers the burden of illness as perceived by patients. Observed patient related outcomes are those in which self-management distinguishes itself from usual asthma care, even under conditions where room for improvement initially seemed limited.

\section{Authors' affiliations}

B P A Thoonen, T R J Schermer, G van den Boom, R P Akkermans, C van Weel, C P van Schayck*, Department of General Practice/Family Medicine, University Medical Centre Nijmegen, The Netherlands

J Molema, H Folgering, University Lung Centre Dekkerswald, University Medical Centre Nijmegen, The Netherlands

R Grol, Centre for Quality of Care Research, University of Maastricht and University Medical Centre Nijmegen, The Netherlands.

This research project has been made possible by research grants from The Netherlands Organization for Scientific Research (NWO) and ASTRAZeneca Pharmaceutica BV.

Conflicts of interest: none.

\section{REFERENCES}

1 Barnes PJ, Jonsson B, Klim JB. The costs of asthma. Eur Respir J 1996; 9:636-42.

2 Bone RC. Goals of asthma management. A step-care approach. Chest 1996; 109: 1056-65.

3 British Thoracic Society. Guidelines on the management of asthma. Thorax 1993;48:S1-24.

4 British Thoracic Society. The British guidelines on asthma management: 1995 review and position statement. Thorax 1997;52(Suppl 1):S1-21

5 National Heart, Lung and Blood Institute. Global strategy for asthma management and prevention. NHLBI/WHO workshop report 95-3659. Bethesda, Maryland: National Heart, Lung and Blood Institute, 1995.

6 Cochrane GM. Compliance and outcomes in patients with asthma. Drugs 1996;52(Suppl): 12-9

7 Bosley CM, Parry DT, Cochrane GM. Patient compliance with inhaled medication: does combining beta-agonists with corticosteroids improve compliance? Eur Respir J 1994;7:504-9.

8 Yeung M, O'Connor SA, Parry DT, et al. Compliance with prescribed drug therapy in asthma. Respir Med 1994;88:31-5.

9 Dompeling E, van Grunsven PM, van Schayck CP, et al. Treatment with inhaled steroids in asthma and chronic bronchitis: long-term compliance and inhaler technique. Fam Pract 1992:9:161-6.

10 Horn CR, Clark TJ, Cochrane GM. Compliance with inhaled therapy and morbidity from asthma. Respir Med 1990;84:67-70.

11 Juniper EF, Guyatt GH, Epstein RS, et al. Evaluation of impairment of health related quality of life in asthma: development of a questionnaire for use in clinical trials. Thorax 1992;47:76-83.

12 Juniper EF, Guyatt GH, Ferrie PJ, et al. Measuring quality of life in asthma. Am Rev Respir Dis 1993;147:832-8.

13 van Schayck CP, van den Broek PJ, den Otter JJ, et al. Periodic treatment regimens with inhaled steroids in asthma or chronic obstructive pulmonary disease. Is it possible? JAMA 1995;274:161-4.

14 van Grunsven PM, Dompeling E, van Schayck CP, et al. Treatment of mild asthma with inhaled corticosteroids: is discontinuation of therapy possible? Fam Med 1996;28:46-51.

15 Thoonen BPA, Schermer TR, Akkermans RP, et al. Willingness of patients to perform self-management of asthma and the role of inhaled steroids. Scand J Prim Health Care 2002;20:60-4.

16 Thoonen BPA, Jones KP, van Rooij HA, et al. Self-treatment of asthma: possibilities and perspectives from the practitioner's point of view. Fam Pract 1999;16:117-22.

*Present address: Department of General Practice/Family Medicine, University of Maastricht, The Netherlands. 
17 Thoonen BPA, van Weel C. Role of family physicians in implementing asthma self-management programs. Dis Manage Health Outcomes $2002 ; 10: 141-6$

18 Abdulwadud OA, Abramson M, Light L, et al. Comparison of patients with asthma managed in general practice and in a hospital clinic. Med Aust 1999:171:72-5.

19 Thoonen BPA, Schermer TRJ, Jansen M, et al. Asthma education tailored to individual patient needs can optimise partnerships in asthma self-management. Patient Educ Couns 2002;47:355-60

20 Geijer RMM, van Hensbergen W, Bottema BJAM et al. NHG-Standaard astma bii volwassenen: behandeling. (NHG guideline on asthma in adults: treatment). Huisarts Wet 1997;40:443-54

21 van der Waart MAC, Dekker FW, Nijhoff S, et al. NHG-standaard CARA bij volwassenen: behandeling (NHG guideline on CNSLD in adults: treatment). Huisarts Wet 1992;35:437-43.

22 Sterk PJ, Fabbri LM, Quanjer PH, et al. Airway responsiveness. Standardized challenge testing with pharmacological, physical and sensitizing stimuli in adults. Eur Respir J 1993;6(Suppl 16):53-83.

$23 \mathrm{Bijl} \mathrm{HI,} \mathrm{Folgering} \mathrm{HT,} \mathrm{van} \mathrm{den} \mathrm{Hoogen} \mathrm{H}$, et al. Perception of bronchoconstriction in asthma patients measured during histamine challenge test. Eur Respir J 1999;14:1049-54.

24 Lipworth BJ. Pharmacokinetics of inhaled drugs. Br J Clin Pharmacol 1996;42:697-705
25 van der Palen J, Klein JJ. Self-management of asthma by adults. Development and evaluation of a program with an emphasis on self-treatment of exacerbations. Medisch Spectrum Twente, 1998.

26 Diggle PJ, Liang KY, Zeger SL. Analysis of longitudinal data. Oxford: Oxford University Press, 1994

27 Litell RC, Milliken GA, Stroup WW, et al. SAS system for mixed models. Cary, NC: SAS Institute Inc, 1996.

28 Anie KA, Jones PW, Hilton SR, et al. A computer-assisted telephone interview technique for assessment of asthma morbidity and drug use in adult asthma. J Clin Epidemiol 1996:49:653-6.

29 Walsh LJ, Wong CA, Cooper S, et al. Morbidity from asthma in relation to regular treatment: a community based study. Thorax 1999:54:296-300.

30 Geijer RMM, Thiadens HA, Smeele UM, et al. NHG-Standaard COPD en astma bij volwassenen: diagnostiek (NHG guidelines on asthma and COPD: diagnosis). Huisarts Wet 1997:40:416-29.

31 Hoskins G, Neville RG, Smith $B$, et al. Do self-management plans reduce mordibity in patients with asthma? Br J Gen Pract 1996;46:169-71.

32 Jones KP, Mullee MA, Middleton M, et al. Peak flow based asthma self-management: a randomised controlled study in general practice. Thorax 1995;50:851-7.

\section{LUNG ALERT}

\section{Decreases in air pollutants may lead to lower cardiopulmonary mortality}

$\Delta$ Clancy L, Goodman P, Sinclair H, et al. Effect of air pollution control on death rates in Dublin, Ireland: an intervention study. Lancet 2002;360:1210-4

ir pollution, deaths, and the weather were compared for 72 months before and 72 months after the $\Delta$ ban on coal sales in the city of Dublin on 1 September 1990. This led to a fall in black smoke of $-35.6 \mu \mathrm{g} / \mathrm{m}^{3}(70 \%)$ and a fall in sulphur dioxide levels of 33\%. Age standardised death rates were adjusted to the 1991 Irish census population. Cardiovascular deaths accounted for $45 \%$ and respiratory deaths for $15 \%$ of non-trauma deaths. Total non-trauma deaths fell by $5.7 \%$, cardiovascular deaths by $10.3 \%$, and respiratory deaths by $15.5 \%(\mathrm{p}<0.001$ in all cases $)$. This amounted to 243 fewer cardiovascular deaths and 116 fewer respiratory deaths per year after the ban.

This study shows substantially larger effect estimates compared with the effect sizes from daily time series mortality studies, strongly suggesting a long term cumulative effect of air pollution exposure.

A Bhowmik 